\title{
Early venous thromboembolism at the beginning of palliative chemotherapy is a poor prognostic factor in patients with metastatic pancreatic cancer: a retrospective study
}

\author{
Jung Sun Kim', Eun Joo Kang ${ }^{1 *}$ (D) Dae Sik Kim², Yoon Ji Choi², Suk Young Lee², Hong Jun Kim²,
} Hee Yeon $\mathrm{Seo}^{3}$ and Jun Suk Kim²

\begin{abstract}
Background: This study investigated the prognostic effects of venous thromboembolism (VTE)-related factors in patients with metastatic pancreatic cancer receiving palliative chemotherapy. Predictive factors for VTE were also investigated.
\end{abstract}

Methods: A total of 216 patients diagnosed with metastatic pancreatic cancer who received gemcitabine-based palliative chemotherapy at our institution were retrospectively evaluated.

Results: VTE occurred in 51 (23.6\%) patients during treatment and did not affect survival. However, patients who were diagnosed with VTE at the beginning of chemotherapy showed poor prognosis compared with patients diagnosed with VTE during chemotherapy: all patients (hazard ratio [HR] 1.897, $p=0.008$ ); patients diagnosed with $\operatorname{VTE}(H R=3.768, p=0.001)$. Low serum sodium $(\mathrm{Na})(<135 \mathrm{mmol} / \mathrm{L})$ and high Khorana score $(\geq 3)$ were strong predictive factors of early VTE (odds ratio [OR] 5.109; 95\% confidence interval [95\% Cl] $=1.010-25.845 ; p=0.049$ for Khorana score, OR 10.304; 95\% Cl=1.036-102.466; $p=0.047$ ) for hyponatremia).

Conclusions: Our study demonstrated that occurrence and detection of VTE in the early period of chemotherapy was the most significant VTE-related prognostic factor in patients with metastatic pancreatic cancer receiving chemotherapy. Prediction using the Khorana score and serum Na levels would be helpful in early diagnosis of VTE.

Keywords: Pancreatic cancer, Venous thromboembolism, Prognosis, Predictive value, Chemotherapy, Khorana score, Hyponatremia

\section{Background}

Pancreatic cancer is a highly lethal malignancy and a major cause of cancer-related death. The incidence of pancreatic cancer continues to increase worldwide, but improvements in patient survival have been dismal. The median overall survival (OS) of patients with unresectable metastatic pancreatic cancer without treatment is

\footnotetext{
* Correspondence: kkangju11@naver.com

${ }^{1}$ Division of Hematology/Oncology, Department of Internal Medicine, Korea University College of Medicine, 148 Gurodong-ro, Guro-gu, Seoul 08308, South Korea

Full list of author information is available at the end of the article
}

less than 4 months [1]. Despite significant developments in systemic treatment for patients with advanced pancreatic cancer, most patients survive less than 1 year and the 5-year survival rate is less than $10 \%$ [2].

Cancer is a well-known risk factor for venous thromboembolism (VTE). The risk of VTE is 4- to 7-fold higher in patients with cancer compared to patients without cancer [3]. Among various cancer types, pancreatic cancer is associated with the highest risk of VTE occurrence [4]. Moreover, chemotherapy further increases the risk of VTE [5]. Therefore, patients with

(c) The Author(s). 2018 Open Access This article is distributed under the terms of the Creative Commons Attribution 4.0 International License (http://creativecommons.org/licenses/by/4.0/) which permits unrestricted use, distribution, and reproduction in any medium, provided you give appropriate credit to the original author(s) and the source, provide a link to the Creative Commons license, and indicate if changes were made. The Creative Commons Public Domain Dedication waiver (http://creativecommons.org/publicdomain/zero/1.0/) applies to the data made available in this article, unless otherwise stated. 
advanced pancreatic cancer receiving chemotherapy are at very high risk of VTE.

The characteristics of cancer-related VTE in terms of anatomical site, symptoms, and complications differ widely. VTE is fatal in some patients, while others experience no discomfort associated with VTE during cancer treatment. In general, cancer-related VTE leads to poor survival in patients with cancer [6]. However, specific VTE-related factors that significantly affect prognosis have not been identified in patients with advanced pancreatic cancer. Furthermore, predictors for significant VTE-related factors that might affect survival are currently unknown in this population. In actual clinical practice, oncologists should determine appropriate anticoagulation treatment in patients according to whether VTE occurred before or during chemotherapy. Anticoagulant therapy may have fatal side effects such as bleeding, which can interrupt cancer treatment and lead to mortality. Decisions regarding anticoagulant therapy are difficult even when patients are diagnosed with VTE; thus, anticoagulation treatment should be provided based on individual patient characteristics. Information regarding prognostic VTE-related factors and predictors would assist oncologists in predicting the occurrence of VTE and in determining active cancer treatment as well as anticoagulant therapy in clinical practice.

The efficacy of prophylactic anticoagulation in patients at high risk for VTE is also under debate. In previous clinical trials, routine thromboprophylaxis in patients with pancreatic cancer receiving chemotherapy did not improve survival outcomes, although primary thromboprophylaxis decreased the incidence of VTE [7]. Therefore, routine thromboprophylaxis is not recommended for all patients with pancreatic cancer, even those at very high risk of VTE $[8,9]$. Additional investigation is thus required to identify a subgroup of patients among all of those at high-risk of VTE for whom thromboprophylaxis may be beneficial.

Therefore, in the present study, we attempted to identify particular characteristics of VTE that are associated with poor survival in patients with metastatic pancreatic cancer receiving palliative chemotherapy. We also attempted to identify clinical factors to predict patients with VTE-related risk factors that can be related to poor survival.

\section{Methods}

\section{Patients and methods}

The medical records of patients with pancreatic cancer diagnosed at the Korea University Guro Hospital between January 2005 and December 2015 were reviewed. Among the patients identified, those with inoperable, recurrent, or metastatic pancreatic cancer who received palliative chemotherapy were consecutively included in this retrospective study. Baseline and clinical data from the time of initial cancer diagnosis until December 31, 2016 were retrieved.

Electronic medical records of patients were reviewed, and the clinical information for each patient, including demographic data, body mass index (BMI), body surface area (BSA), history of diabetes mellitus (DM), site of primary mass, previous surgery, Eastern Cooperative Oncology Group Performance Status (ECOG PS), treatment history, laboratory findings at the beginning of chemotherapy, and VTE occurrence, were investigated. Measurement of inflammatory markers, such as the neutrophil-to-lymphocyte ratio (NLR) and platelet-to-lymphocyte ratio (PLR), prior to the initiation of chemotherapy, were also examined. In addition, we focused on variables included in Khorana's predictive model and calculated the Khorana score, which is a popular tool for VTE risk prediction in patients with cancer receiving chemotherapy [4]. According to Khorana's model, pancreatic cancer is associated with a significantly high risk for VTE development, with a base score of 2. In addition, pre-chemotherapy platelet (PLT) count $>350,000 /$ $\mu \mathrm{L}$ and white blood cell (WBC) count $>11,000 / \mu \mathrm{L}$, hemoglobin $(\mathrm{Hb})$ level $<10 \mathrm{~g} / \mathrm{dL}$, use of red cell growth factors, and BMI $\geq 35 \mathrm{~kg} / \mathrm{m}^{2}$ are significant risk factors, with each corresponding to a score of 1 in Khorana's predictive model. Regarding BMI, the number of patients with values $\geq 35 \mathrm{~kg} / \mathrm{m}^{2}$ or higher among Asian patients with pancreatic cancer were expected to be very low. In this study, only one patient had a BMI in this range; therefore, we reduced the cut-off to $\geq 30 \mathrm{~kg} / \mathrm{m}^{2}$, which is regarded as a criterion for obesity. We were unable to compare the use of red cell growth factors, because all patients included in this study were not prescribed red cell growth factors during chemotherapy. According to Khorana's model, patients with a score $>3$ were classified as high-risk, while those with a score of 2 were classified as the intermediate-risk group.

\section{Venous thromboembolism diagnosis}

To collect information regarding VTE occurrence, computed tomography $(\mathrm{CT})$ and magnetic resonance imaging (MRI) scans of the chest, abdomen and pelvis, extremities, and brain and ultrasonography scans of the extremities were reviewed. If patient was suspected to have VTE, lower extremity CT venography and/or CT pulmonary angiography was performed. From these imaging results, all VTE events including deep vein thrombosis (DVT), pulmonary embolism (PE), visceral venous thrombosis (VVT), and central venous catheter-related thrombosis were collected. Because serial chest, abdomen, and pelvic CT were performed on all patients at around 6-8 weeks intervals during chemotherapy, we could obtain complete information regarding VTE such as detection day; location; and symptom presence, existence, and disappearance. Because early onset or synchronous VTE with 
cancer can affect whole cancer prognosis, treatment and quality of life, we divided patients into early VTE and late VTE group and analyzed. Patients diagnosed with VTE within 30 days from the start of palliative chemotherapy were assigned to the early VTE group, whereas those diagnosed with VTE at least 30 days after the beginning of palliative chemotherapy were assigned to the late VTE group. Information regarding the presence of symptoms and treatments for VTE was obtained through electronic medical records. This study was approved by the Institutional Review Board of the Korea University Guro Hospital (KUGH 16320-001).

\section{Statistical analysis}

Associations between characteristics of patients with or without VTE were investigated using the Chi-square test. The prognostic effect of VTE on survival was also analyzed. Survival was calculated using the Kaplan-Meier method. OS from chemotherapy was defined as the time from the beginning of palliative chemotherapy for pancreatic cancer to death from any cause. OS from VTE was defined as the time from VTE diagnosis to death from any cause. Comparisons between different characteristics were made using the log-rank test. To evaluate the impact of VTE occurrence on OS and to investigate independent prognostic factors, (variables with $p<0.05$ ) we investigated using the time-dependent covariate multiple Cox model. Also, Cox proportional hazard model was used to evaluate the impact of early VTE on OS and to investigate independent prognostic factors. Moreover, associations between characteristics of patients with or without synchronous VTE were investigated using the Chi-square test. Multivariate logistic regression was performed with variables that showed significance using the Chi-square test. All statistical analyses were performed using IBM SPSS Statistics for Windows, version 21.0 (IBM Corp., Armonk, NY, USA).

\section{Results}

\section{Patient characteristics}

Of the 326 patients with pancreatic cancer who received palliative chemotherapy at our institution, data for 216 patients with metastatic pancreatic cancer were retrieved and analyzed. The median age of the patients included in the study was 63 years (range, 38-83).

All patients received gemcitabine alone or gemcitabine-based combination chemotherapy as the first-line treatment: gemcitabine only (8.3\%), gemcitabine + erlotinib (35.2\%), gemcitabine + fluorouracil (capecitabine, TS-1, or tegafur/uracil 46.3\%), gemcitabine + platinum (oxaliplatin or carboplatin, $1.4 \%)$, gemcitabine + nab-paclitaxel $(0.5 \%)$, gemcitabine $+/-$ clinical trial agents included in phase III studies (8.3\%).
Of the 216 patients, 51 (23.6\%) experienced VTE during treatment courses. Characteristics of all patients and comparison of the characteristics of patients with and without VTE are shown in Table 1. The characteristics of patients with and without VTE were not significantly different.

\section{Characteristics of venous thromboembolism}

The characteristics of VTE are shown in Table 2. According to the site of VTE, VVT was the most common, occurring in 26 patients (51\% of 51 VTE patients, $12 \%$ of all patients). Among all VTE patients, PE occurred in $15(25.5 \%)$, and DVT occurred in $8(13.7 \%)$. In terms of the time of VTE diagnosis, 23 patients $(41.8 \%$ of $51 \mathrm{VTE}$ patients and $10.6 \%$ of all patients) were included in the early VTE group. Meanwhile, the late VTE group included 28 patients $(58.2 \%$ of 51 VTE patients and $13.0 \%$ of all patients). In both the early VTE and late VTE groups, VVT was the most common, followed by PE. Symptomatic VTE occurred in 15 patients $(29.4 \%$ of VTE patients), whereas asymptomatic VTE was detected in 36 patients (70.6\% of VTE patients). In symptomatic VTE, DVT was the most common, whereas VVT was the most common in asymptomatic VTE. Among the 51 VTE patients, anticoagulation treatment was administered to 15 patients $(29.4 \%)$ using low-molecular-weight heparin, warfarin, and rivaroxaban. In the early VTE group, 9 patients $(39.1 \%)$ received anticoagulation treatment and $6(21.4 \%)$ received anticoagulation treatment in the late VTE group. In addition, among the 51 VTE patients, 32 patients $(62.7 \%)$ continued chemotherapy after VTE diagnosis. Nineteen patients (37.3\%) stopped chemotherapy and received supportive care because their general performance deteriorated simultaneously with VTE detection. Among the 19 patients who stopped chemotherapy, only 4 patients received anticoagulation treatment for a short period of approximately 2 weeks. These patients passed away within 6 weeks.

\section{Survival and prognostic factors of all patients and patients with venous thromboembolism}

The median OS of the 216 patients who received palliative chemotherapy was 6.2 months (95\% confidence interval $[\mathrm{CI}]=5.485-6.915)$, and the median OS of 51 patients with VTE who received palliative chemotherapy was 5.9 months $(95 \% \mathrm{CI}=3.401-8.399)$. The median time from diagnosis of metastatic pancreatic cancer to VTE diagnosis was 2.2 months. In patients diagnosed with VTE, the median OS from the VTE diagnosis to death was only 2.4 months $(95 \% \mathrm{CI}=1.5-3.3)$. VTE occurrence did not affect the duration of OS from the start of chemotherapy $(p=0.776)$. In addition, the presence of a central venous catheter and VTE-related symptoms or location of the VTE did not affect OS. However, a 
Table 1 Characteristics of patients $(N=216)$

\begin{tabular}{|c|c|c|c|c|c|c|}
\hline & \multicolumn{2}{|c|}{ No VTE } & \multicolumn{2}{|c|}{ VTE } & \multirow{2}{*}{$\begin{array}{l}\text { Total } \\
\mathrm{N}\end{array}$} & \multirow[t]{2}{*}{$P$-value } \\
\hline & $N$ & $\%$ & $N$ & $\%$ & & \\
\hline \multicolumn{7}{|l|}{ Age, median (range) } \\
\hline$<70$ years & 113 & 75.3 & 37 & 24.7 & 150 & \multirow[t]{2}{*}{0.425} \\
\hline$\geq 70$ years & 53 & 80.3 & 13 & 19.7 & 66 & \\
\hline \multicolumn{7}{|l|}{ Sex } \\
\hline Male & 108 & 82.4 & 23 & 17.6 & 131 & \multirow[t]{2}{*}{0.016} \\
\hline Female & 58 & 68.2 & 27 & 31.8 & 85 & \\
\hline \multicolumn{7}{|l|}{ BSA } \\
\hline$<1.8 \mathrm{~m}^{2}$ & 153 & 78.1 & 43 & 21.9 & 196 & \multirow[t]{2}{*}{0.187} \\
\hline$\geq 1.8 \mathrm{~m}^{2}$ & 13 & 65 & 7 & 35 & 20 & \\
\hline \multicolumn{7}{|l|}{ BMI } \\
\hline$<30 \mathrm{~kg} / \mathrm{m}^{2}$ & 162 & 77.1 & 48 & 22.9 & 210 & \multirow[t]{2}{*}{0.549} \\
\hline$\geq 30 \mathrm{~kg} / \mathrm{m}^{2}$ & 4 & 66.7 & 2 & 33.3 & 6 & \\
\hline \multicolumn{7}{|l|}{ DM } \\
\hline No & 90 & 73.2 & 33 & 26.8 & 123 & \multirow[t]{2}{*}{0.14} \\
\hline Yes & 76 & 81.7 & 17 & 18.3 & 93 & \\
\hline \multicolumn{7}{|l|}{ Site of primary mass: } \\
\hline Head & 80 & 79.2 & 21 & 20.8 & 101 & \multirow[t]{3}{*}{0.506} \\
\hline Body & 28 & 80 & 7 & 20 & 35 & \\
\hline Tail & 58 & 72.5 & 22 & 27.5 & 80 & \\
\hline \multicolumn{7}{|l|}{ Previous surgery: } \\
\hline Palliative & 10 & 83.3 & 2 & 16.7 & 12 & \multirow[t]{2}{*}{0.584} \\
\hline None & 156 & 76.5 & 48 & 23.5 & 204 & \\
\hline \multicolumn{7}{|l|}{ ECOG PS } \\
\hline $0-1$ & 150 & 76.5 & 46 & 23.5 & 196 & \multirow[t]{2}{*}{0.726} \\
\hline $2-3$ & 16 & 80 & 4 & 20 & 20 & \\
\hline \multicolumn{7}{|l|}{ WBC } \\
\hline$<11,000 / \mu \mathrm{L}$ & 136 & 75.1 & 45 & 24.9 & 181 & \multirow[t]{2}{*}{0.174} \\
\hline$\geq 11,000 / \mu \mathrm{L}$ & 30 & 85.7 & 5 & 14.3 & 35 & \\
\hline \multicolumn{7}{|l|}{$\mathrm{Hb}$} \\
\hline$<10 \mathrm{~g} / \mathrm{dL}$ & 31 & 68.9 & 14 & 31.1 & 45 & 0.404 \\
\hline$\geq 10 \mathrm{~g} / \mathrm{dL}$ & 193 & 74.8 & 65 & 25.2 & 258 & \\
\hline PLT & & & & & & 0.091 \\
\hline$<350,000 / \mu \mathrm{L}$ & 148 & 78.7 & 40 & 21.3 & 188 & \\
\hline$\geq 350,000 / \mu \mathrm{L}$ & 18 & 64.3 & 10 & 35.7 & 28 & \\
\hline CA19-9 & & & & & & \\
\hline$<1000 \mathrm{U} / \mathrm{mL}$ & 88 & 75.2 & 29 & 24.8 & 117 & 0.535 \\
\hline$\geq 1000 \mathrm{U} / \mathrm{mL}$ & 78 & 78.8 & 21 & 21.2 & 99 & \\
\hline Khorana score & & & & & & \\
\hline Intermediate-risk (2) & 105 & 77.8 & 30 & 22.2 & 135 & 0.677 \\
\hline High-risk ( $\geq 3$ ) & 61 & 75.3 & 20 & 24.7 & 81 & \\
\hline CVC insertion & & & & & & \\
\hline No & 32 & 69.6 & 14 & 30.4 & 46 & 0.219 \\
\hline Yes & 133 & 78.2 & 37 & 21.8 & 170 & \\
\hline
\end{tabular}

Table 1 Characteristics of patients $(N=216)$ (Continued)

\begin{tabular}{|c|c|c|c|c|c|c|}
\hline & \multicolumn{2}{|c|}{ No VTE } & \multicolumn{2}{|l|}{ VTE } & \multirow{2}{*}{$\begin{array}{l}\text { Total } \\
N\end{array}$} & \multirow[t]{2}{*}{$P$-value } \\
\hline & $N$ & $\%$ & N & $\%$ & & \\
\hline \multicolumn{7}{|c|}{ Chemotherapy more than first-line } \\
\hline$\geq$ Second-line & 68 & 81 & 16 & 19 & 84 & 0.205 \\
\hline First-line only & 88 & 72.7 & 33 & 27.3 & 121 & \\
\hline Unknown & 10 & 90.9 & 1 & 9.1 & 11 & \\
\hline \multicolumn{7}{|c|}{ Number of metastatic organs } \\
\hline$<3$ & 40 & 85.1 & 7 & 14.9 & 47 & 0.129 \\
\hline$\geq 3$ & 126 & 74.6 & 43 & 25.4 & 169 & \\
\hline
\end{tabular}

$B S A$ body surface area, $B M I$ body mass index, DM diabetes mellitus, ECOG PS Eastern Cooperative Oncology Group Performance Status, WBC white blood cell, $H b$ hemoglobin, PLT platelet, CA19-9 cancer antigen 19-9, CVC, central venous catheter

survival difference was observed based on the time of VTE diagnosis. In patients with early VTE, the median OS was significantly longer than in patients with late VTE or no VTE $(p=0.005)$ (Fig. 1a). The median OS of patients with early VTE was 3.7 months, however, the median OS of patients with late VTE was 9.8 months and that of patients without VTE was 6.3 months $(p=0.008)$ (Fig. 1b). In addition, the median progression-free survival (PFS) differed between the two groups. Patients with early VTE showed a significantly shorter PFS compared to patients with late VTE or no VTE (median PFS; 1.6 vs. 4.6 vs. 3.2 months, $p<0.001$ ).

The prognostic factors of all patients were investigated. To investigate of impact of VTE occurrence and other variables to OS, we analyzed using time-dependent multivariate Cox model. In that analysis, VTE occurrence itself did not show an association with poor OS $(p=0.711)$. However, early VTE ( $p=0.001$ for time of VTE occurrence) worse ECOG PS $(2-3)(p=0.004)$, higher NLR $\geq 2.7 \quad(p=0.048)$, low serum $\mathrm{Na}$ level $<135 \mathrm{mmol} / \mathrm{L}(p=0.022)$, higher serum CA 19-9 level with $<1000 \mathrm{U} / \mathrm{mL}(p=0.041)$, and presence of liver metastases $(p=0.046)$ were independent poor prognostic factors in multivariate Cox analysis (Table 3). Patients with early VTE had 1.897 times higher-risk of poor OS than patients with late VTE or no VTE (Table 3).

The prognostic factors among patients diagnosed with VTE were investigated because these factors might be helpful to predict survival and to determine active treatment in this patient group. We found that early $\operatorname{VTE}(p=0.001)$ was also an independent poor prognostic factor, as well as the number of metastatic organs $\geq 3$ involved $(p=0.007)$ in patients with VTE. Among patients with VTE, those with early VTE had 3.768-fold higher risk of poor OS than those with late VTE (Table 4). Similar to the results for the entire patient group, other VTE-related factors including the Khorana score, VTE site, symptoms, and anticoagulant therapy were not statistically significant. 
Table 2 Characteristics of venous thromboembolism in the study sample $(N=51)$

\begin{tabular}{|c|c|c|c|c|}
\hline & Early VTE & Late VTE & Total VTE & \\
\hline & $N(\%$, of all VTE) & N (\%, of all VTE) & $N(\%$, of all VTE) & $\%$ (of all patients) \\
\hline Site of VTE: & & & & \\
\hline DVT & $3(5.9)$ & $4(7.8)$ & $7(13.7)$ & 3.2 \\
\hline PE & $5(9.8)$ & $8(15.7)$ & $13(25.5)$ & 6.0 \\
\hline WT & $12(23.5)$ & $14(27.5)$ & $26(51)$ & 12.0 \\
\hline$P E+D V T$ & $3(5.9)$ & $0(0)$ & $3(5.9)$ & 1.4 \\
\hline CVC related & $0(0)$ & $2(3.9)$ & $2(3.9)$ & 0.9 \\
\hline Total & $23(45.1)$ & $28(54.9)$ & $51(100)$ & 23.6 \\
\hline Symptoms: & & & & \\
\hline Symptomatic & $7(13.7)$ & $8(15.7)$ & $15(29.4)$ & 6.9 \\
\hline Asymptomatic & $16(31.4)$ & $20(39.2)$ & $36(70.6)$ & 16.7 \\
\hline Total & $23(45.1)$ & $28(54.9)$ & $51(100)$ & 23.6 \\
\hline Coagulation & & & & \\
\hline Yes & $9(17.6)$ & $6(11.8)$ & $15(29.4)$ & 6.9 \\
\hline No & $14(27.5)$ & $22(43.1)$ & 36 (70.6) & 16.7 \\
\hline Total & $23(45.1)$ & $28(54.9)$ & $51(100)$ & 23.6 \\
\hline Time from the adv & tic cancer to VTE d & ths) & & \\
\hline Median (range) & & & & $2.2(1.9-2.7)$ \\
\hline Overall survival fro & (months) & & & \\
\hline Median (range) & & & & $2.4(1.5-3.3)$ \\
\hline
\end{tabular}

VTE venous thromboembolism, DVT deep vein thrombosis, $P E$ pulmonary embolism, $C /$ cerebral infarction, $V V T$ visceral venous thrombosis, $C V C$ central venous catheter
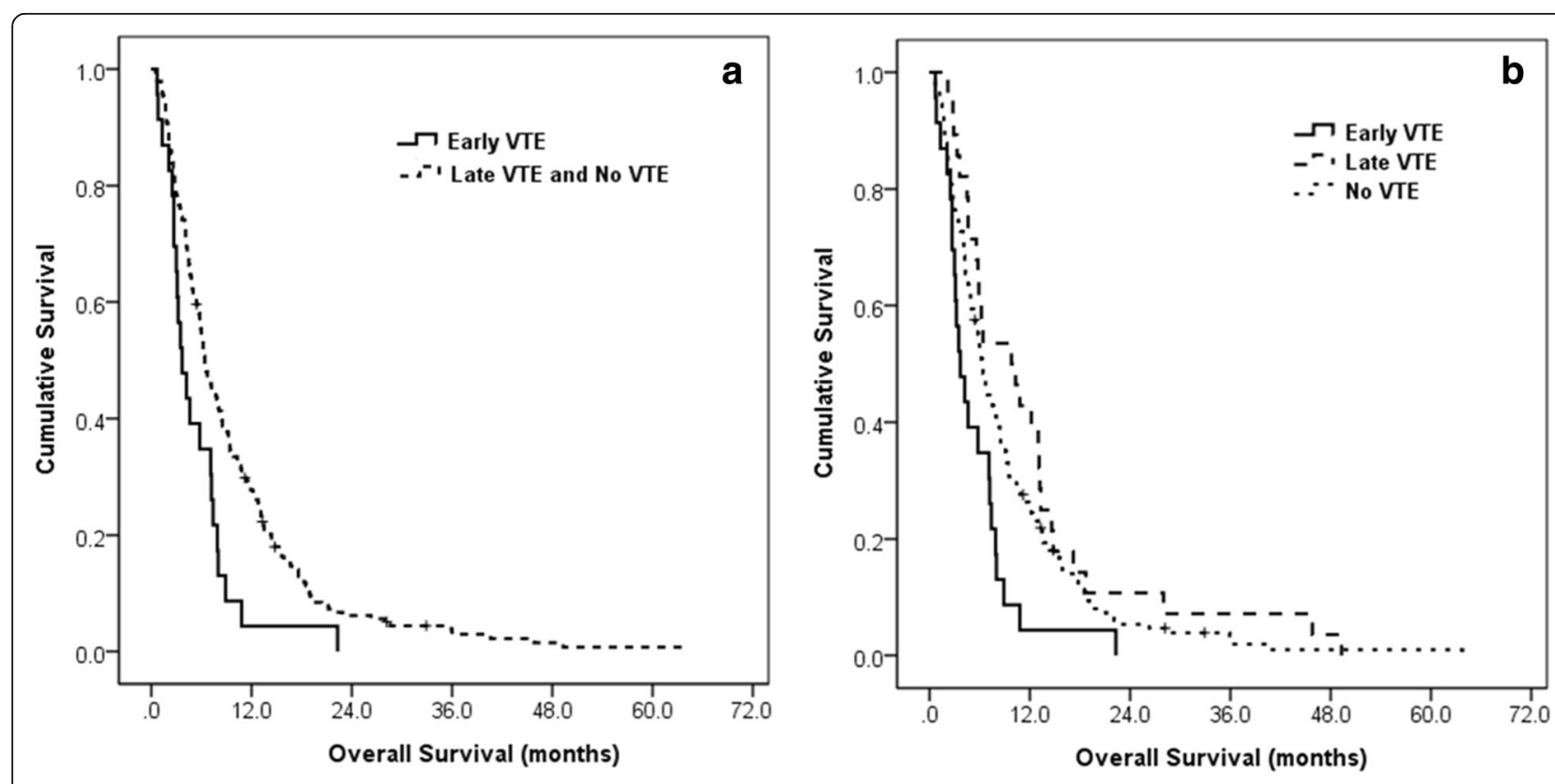

Fig. 1 Overall survival curves of all patients who received palliative chemotherapy according to venous thromboembolism occurrence. a Median OS of patents with early VTE was 3.7 months (95\% Cl, 2.135-5.265); that of patients with late VTE or without VTE was 6.4 months (95\% Cl, 5.522$7.278, p=0.005)$. bMedian OS of patents with early VTE was 3.7 months $(95 \% \mathrm{Cl}, 2.135-5.265)$; that of patients with late VTE was 9.8 months $(95 \%$ $\mathrm{Cl}, 3.836-15.764)$ and that of patients without VTE was 6.3 months ( $95 \% \mathrm{Cl}, 5.493-7.107, p=0.008)$. 
Table 3 Multivariate analysis of prognostic factors in all patients $(N=216)$

\begin{tabular}{|c|c|c|c|}
\hline & \multicolumn{3}{|c|}{ Overall survival (OS) } \\
\hline & Hazard ratio & $95 \% \mathrm{Cl}$ & P-value \\
\hline Time of VTE occurrence (early vs. late and no VTE) & 1.897 & $1.183-3.040$ & 0.008 \\
\hline Khorana score (high-risk vs. intermediate-risk) & 0.967 & $0.622-1.504$ & 0.881 \\
\hline ECOG PS (2-3 vs 0-1) & 2.118 & $1.267-3.541$ & 0.004 \\
\hline NLR $(\geq 2.7$ vs. $<2.7)$ & 1.432 & $1.003-2.046$ & 0.048 \\
\hline PLR $(\geq 180$ vs. $<180)$ & 1.257 & $0.884-1.787$ & 0.202 \\
\hline WBC $(\geq 11,000 / \mu \mathrm{Lvs} .<11,000 / \mu \mathrm{L})$ & 1.29 & $0.788-2.113$ & 0.311 \\
\hline $\mathrm{Hb}(<10 \mathrm{~g} / \mathrm{dL}$ vs. $\geq 10 \mathrm{~g} / \mathrm{dL})$ & 1.242 & $0.760-2.030$ & 0.387 \\
\hline $\mathrm{Na}(<135 \mathrm{mmol} / \mathrm{L}$ vs. $\geq 135 \mathrm{mmol} / \mathrm{L})$ & 1.61 & $1.070-2.422$ & 0.022 \\
\hline Albumin $(<3.5 \mathrm{~g} / \mathrm{dL}$ vs. $\geq 3.5 \mathrm{~g} / \mathrm{dL})$ & 1.036 & $0.691-1.552$ & 0.865 \\
\hline CA19-9 ( $\geq 1000 \mathrm{U} / \mathrm{mL}$ vs. $<1000 \mathrm{U} / \mathrm{mL})$ & 1.364 & $1.013-1.836$ & 0.041 \\
\hline Liver metastases (Yes vs. No) & 1.382 & $1.006-1.899$ & 0.046 \\
\hline Number of metastatic organs $(\geq 3$ vs. $<3$ ) & 0.752 & $.0521-1.086$ & 0.129 \\
\hline
\end{tabular}

NLR Neutrophil-to-lymphocyte ratio, PLR platelet-to-lymphocyte ratio, $H b$ hemoglobin, CA19-9 cancer antigen 19-9, WBC White blood cell

\section{Predictive factors associated with early venous thromboembolism diagnosis}

Because the survival of patients with early VTE was significantly worse than that of patients without VTE or late VTE, the clinical characteristics of patients with early VTE and late VTE or no VTE were compared (Table 5). Age, sex, BSA, disease status, previous surgery, ECOG PS, CA 19-9 before chemotherapy, and number of metastatic organs did not show any differences between the two groups. However, the proportion of patients with serum $\mathrm{Na}$ level $<135 \mathrm{mmol} / \mathrm{L}$ was higher in patients with early VTE $(p=0.008)$. Among the variables included in the Khorana's prediction model, high PLT counts $(\geq 350,000 / \mu \mathrm{L})$ were observed in a higher proportion of patients with early VTE $(p=0.008)$. In addition, the proportion of patients in the high-risk group (Khorana score $\geq 3$ ) was higher in the early VTE group $(p=0.014)$. Multivariate analysis using a logistic regression model showed that classification into the high-risk group, with Khorana score $\geq 3$ and hyponatremia with serum $\mathrm{Na}$ levels $<135 \mathrm{mmol} / \mathrm{L}$ was strongly associated with the occurrence of synchronous VTE (odds ratio [OR] 5.109; 95\% CI $=1.010-25.845 ; p=0.049$ for Khorana score, OR 10.304; 95\% CI $=1.036-102.466 ; p=0.047$ for hyponatremia).

\section{Discussion}

VTE is a common complication of pancreatic cancer. However, data regarding the incidence, characteristics, or survival of patients with metastatic pancreatic cancer with VTE who receive palliative chemotherapy are limited. In the present study, the incidence of VTE was $23.6 \%$, which was similar to that of previous reports. A randomized controlled study of patients with pancreatic cancer receiving chemotherapy performed to assess the value of simultaneous thromboprophylaxis with chemotherapy found that VTE incidence during the trial in the no thromboprophylaxis group was $28 \%$ [10]. In another retrospective study, the incidence of VTE in patients with pancreatic cancer receiving chemotherapy was $35.7 \%$ [11]. In the present

Table 4 Multivariate analysis of prognostic factors in patients with venous thromboembolism $(N=51)$

\begin{tabular}{llll}
\hline & Overall survival (OS) & & \\
\cline { 2 - 4 } & Hazard ratio & $95 \% \mathrm{Cl}$ & $1.705-8.328$ \\
\hline Time of VTE occurrence (early vs. late) & 3.768 & $0.454-2.224$ & 0.001 \\
Khorana score (high-risk vs. intermediate-risk) & 1.005 & $1.640-21.665$ & 0.990 \\
Number of metastatic organs ( $\geq 3$ vs. $<3)$ & 5.961 & $0.344-4.739$ & 0.007 \\
$\mathrm{Hb}(<10 \mathrm{~g} / \mathrm{dL}$ vs. $\geq 10 \mathrm{~g} / \mathrm{dL})$ & 1.277 & $0.334-2.496$ & 0.714 \\
$\mathrm{Na}(<135 \mathrm{mmol} / \mathrm{L}$ vs. $\geq 135 \mathrm{mmol} / \mathrm{L})$ & 0.913 & $0.482-5.343$ & 0.859 \\
Albumin $(<3.5 \mathrm{~g} / \mathrm{dL}$ vs. $\geq 3.5 \mathrm{~g} / \mathrm{dL})$ & 1.605 & $0.920-3.289$ & 0.441 \\
$\mathrm{CA} 19-9(\geq 1000 \mathrm{U} / \mathrm{mL}$ vs. $<1000 \mathrm{U} / \mathrm{mL})$ & 1.74 & $0.909-3.651$ & 0.088 \\
Lung metastases $($ Yes vs. No) & 1.822 & & 0.091 \\
\hline
\end{tabular}

NLR neutrophil-to-lymphocyte ratio, Hb hemoglobin, CA19-9 cancer antigen 19-9; LN lymph node 
Table 5 Factors associated with early venous thromboembolism $(\mathrm{N}=216)$

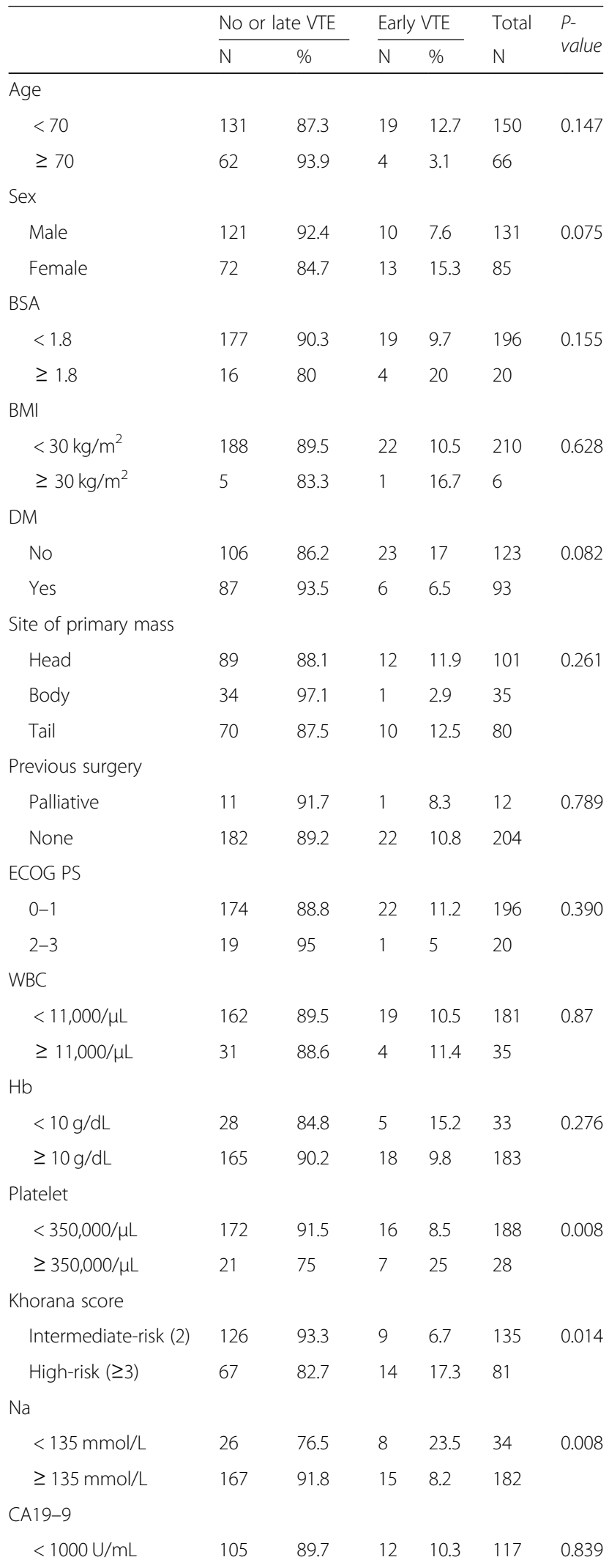

Table 5 Factors associated with early venous thromboembolism ( $\mathrm{N}=216)$ (Continued)

\begin{tabular}{|c|c|c|c|c|c|c|}
\hline & \multicolumn{2}{|c|}{ No or late VTE } & \multicolumn{2}{|c|}{ Early VTE } & \multirow{2}{*}{$\begin{array}{l}\text { Total } \\
\mathrm{N}\end{array}$} & \multirow{2}{*}{$\begin{array}{l}P \text { - } \\
\text { value }\end{array}$} \\
\hline & N & $\%$ & N & $\%$ & & \\
\hline$\geq 1000 \mathrm{U} / \mathrm{mL}$ & 88 & 88.9 & 11 & 11.1 & 99 & \\
\hline \multicolumn{7}{|c|}{ Number of metastatic organs } \\
\hline$<3$ & 45 & 95.7 & 2 & 4.3 & 47 & 0.108 \\
\hline$\geq 3$ & 148 & 87.6 & 21 & 12.4 & 169 & \\
\hline
\end{tabular}

$B S A$ body surface area, $B M I$ body mass index, DM diabetes mellitus, ECOG PS Eastern Cooperative Oncology Group Performance Status, WBC white blood cell, $H b$ Hemoglobin, PLT platelet, CA19-9 cancer antigen 19-9

study, we found that VTE occurrence itself did not affect the survival of patients with metastatic pancreatic cancer receiving palliative chemotherapy. In general, VTE occurrence is known to lead to poor survival outcomes in patients with cancer. In contrast, some studies have reported that VTE occurrence in patients with pancreatic cancer was not associated with poor survival, which is similar to the results of our study [12, 13]. Furthermore, the most important VTE related prognostic factor in the present analysis was the time of VTE diagnosis, rather than the occurrence of VTE. Patients diagnosed with VTE around the initiation of cancer chemotherapy, defined as early VTE, showed significantly poor survival in this study. The prognosis was even worse in patients with early VTE among the subgroup of patients with VTE, resulting in an almost 4-fold increased risk of death. Nonetheless, most previous studies regarding VTE focused on all VTE events during treatment courses; only one study investigated early VTE in patients with pancreatic cancer receiving chemotherapy. In the study by Mandala et al. comprising 227 patients with nonresectable pancreatic cancer, the incidence of early VTE was $12.3 \%$, [14], which was similar to $10.6 \%$ of the 216 included patients in our study. Although early VTE did not affect the PFS or OS on multivariate analysis in the study of Mandala et al., it was associated with poor response to chemotherapy.

VTE development in patients with cancer results from multifactorial mechanisms. The main pathogenesis is associated with the generation of both intrinsic and extrinsic hypercoagulable status owing to cancer cells. Cancer cells stimulate the coagulation cascade by increasing the production of procoagulant activators such as tissue factor (TF) [15]. The upregulated coagulation cascade affects not only systemic coagulation but also tumor growth and metastasis through activation of angiogenesis signaling pathways [16]. This stimulation of tumor angiogenesis leads to more aggressive tumor progression. A study on pancreatic cancer found that TF is also expressed in pancreatic cancer cells and its expression was associated with poor histologic grade and worse prognosis [17]. Moreover, the expression of TF on tumor 
cells resulted in increased mitogenic activity through enhanced vascular permeability and synthesis of vascular endothelial cell growth factor [18]. Therefore, our analysis suggests that the occurrence of early VTE at the time of cancer diagnosis indicates an enhanced angiogenic condition of the tumor that implies biologically more aggressive characteristics at baseline, thus possibly resulting in poor OS. In addition, a hypercoagulable status has been associated with poor response to chemotherapy [19]. Moreover, additive morbidity owing to VTE and interruption or delay of chemotherapy due to VTE management or anticoagulation treatment may also be associated with poor survival in patients with early VTE.

In addition, a higher number of metastatic organs were also a significant poor prognostic factor among patients with VTE in the present study. High numbers of metastatic organs are associated with a relatively large tumor burden and advanced tumor status, factors that cause poor survival outcome. In previous analyses that included patients with pancreatic cancer from resectable stage to advanced disease, patients with metastatic disease showed a higher risk of death compared to other patients, when they were diagnosed with VTE [12]. Even in the present study, which included only patients with advanced stage pancreatic cancer, patients with a higher number of metastatic organs showed significantly worse prognosis among patients with VTE. Therefore, we should focus on this subgroup of patients with poor prognostic factors to improve survival outcomes. For example, further investigation on the effectiveness of anticoagulation treatment in patients with a higher tumor burden and/or who experience early VTE are necessary. VTE-related prognostic factors in this study might be helpful to select patients for future clinical trials.

Prediction of VTE is important because it encourages greater attention to the occurrence of VTE in patients presenting significant risk factors. In the present study, we focused on investigating the predictors of early VTE because it was a significant poor prognostic VTE-related factor. Among all patients, those with a PLT count > $350,000 / \mu \mathrm{L}$, which is a factor included in Khorana's model, showed a higher incidence of VTE. Increased PLT count is associated with hyperviscosity and has been associated with increased risk of VTE in a previous study [20]. Unexpectedly, a serum $\mathrm{Na}$ level $<135 / \mathrm{mmol}$ was a significant risk factor for occurrence of early VTE in this study. Hyponatremia is not a well-known predictive factor for VTE, but some studies have reported the association of VTE and hyponatremia. In a study of Chinese non-small cell lung cancer patients, the risk of VTE was increased in patients with hyponatremia $(<130 / \mathrm{mmol})$ [21]. In addition, in a study of pediatric patients who underwent orthopedic surgery, hyponatremia was reported as a risk factor for VTE [22]. Nevertheless, the mechanism underlying the association between hyponatremia and early VTE is difficult to explain; however, hyponatremia prior to chemotherapy may reflect poor oral intake or a poor general medical status of the patient, and this state may be associated with a thrombosis-prone condition. Further studies are needed to investigate the mechanisms involved.

In the present study, classification into the high-risk group defined using Khorana's model was also an important predictive marker of early VTE. No difference was observed in the incidence of all VTE between the intermediate- and high-risk groups defined according to Khorana's model; however, a significant difference for the risk of early VTE occurrence was observed. The initial study used to define Khorana's prediction model included patients with various types of cancer [4]. Only 54 (2.0\%) gastric and $19(1.4 \%)$ pancreatic cancer patients were included in the derivation cohort and the validation cohort of that study. Even in other studies for external validation, the number of patients with pancreatic cancer was small $[23,24]$. In addition, according to previous studies, which included only patients with pancreatic cancer, conflicting findings were observed regarding the predictive role of the model. Munoz Martin et al. compared the incidence of VTE detected within 6 months after diagnosis between high- and intermediate-risk groups according to Khorana's model in 84 patients with pancreatic cancer receiving chemotherapy. VTE incidence was higher in the high-risk group (37.5\%) than in the intermediate-risk group (33.3\%) [11]. Conversely, van Es et al. reported that Khorana's model did not discriminate between intermediate risk and high risk of VTE because VTE incidence did not differ between the two groups in their study that included 178 patients with pancreatic cancer receiving chemotherapy [25]. However, we can suggest that Khorana's model has a predictive role particularly for early VTE in patients with pancreatic cancer receiving chemotherapy and our study has value in the validation of the model that included 216 patients, which is by far the greatest number of patients with same disease status included in comparable studies.

In the present study, symptomatic VTE occurred in $6.9 \%$ of patients. In general, symptomatic VTE has received greater attention because it can negatively impact on quality of life, delay cancer treatment, and result in additive anticoagulation treatment. In contrast, asymptomatic VTE has not been a subject of common interest in this field. Nevertheless, symptomatic VTE did not affect OS in the present study. Moreover, two-thirds of patients with early VTE exhibited asymptomatic VTE. Therefore, we suggest that the occurrence and detection time of VTE is more important, regardless of the 
presence of symptoms; VTE screening at the start of palliative chemotherapy should be performed even in patients with no VTE-related symptoms. Some VTEs, such as PE or VVT, can be detected despite the absence of symptoms because patients are required to undergo imaging analysis including chest and abdominopelvic CT to assess their cancer status prior to the initiation of chemotherapy. In addition, laboratory analysis using D-dimer, which is a fibrin degradation product and reflects the activation of hemostasis and fibrinolysis, would be helpful because D-dimer is a well-known and widely available biomarker for screening of VTE in the general population and in some cancer patients [26]. However, the potential use of D-dimer as a predictive factor for VTE in patients with pancreatic cancer receiving palliative chemotherapy has not been reported and further investigation is necessary. Because concordant markers are yet to be confirmed in clinical practice, focusing on the Khorana score, which has been shown to have meaningful significance in predicting the occurrence of VTE, could be helpful, particularly in predicting synchronous VTE, as in our study. Further research regarding the use of coagulation-related markers and clinical factors would be helpful for screening for VTE located outside of the routine CT imaging field or for those with microcoagulable status barely detectable using imaging modalities.

This study is limited by its single institution retrospective design. We could not analyze the association or role of clinical factors with VTE-related or coagulation-related laboratory tests because of insufficient data. We only determined an association of clinical factors and VTE. However, this study has value because of the higher number of patients included compared to other previous studies with a similar objective. The present study should provide the basis for further investigations, such as studies into the role of anticoagulation therapy for patients with pancreatic cancer and early VTE.

\section{Conclusions}

In conclusion, early occurrence and detection of VTE at the beginning of palliative chemotherapy is an important poor prognostic factor for patients with metastatic pancreatic cancer and the Khorana score and serum $\mathrm{Na}$ levels are valuable for predicting the occurrence of early VTE in these patients. Clinicians should be particularly attentive to patients with pancreatic cancer with high Khorana scores and low serum $\mathrm{Na}$ and the occurrence of VTE around the start of chemotherapy. Furthermore, future research to improve survival outcomes for patients who have poor prognostic factors is desperately needed.

\section{Abbreviations}

BMI: Body mass index; BSA: Body surface area; Cl: Confidence interval; CT: Computed tomography; DM: Diabetes mellitus; DVT: Deep vein thrombosis; ECOG PS: Eastern Cooperative Oncology Group Performance Status; Hb: Hemoglobin; MRI: Magnetic resonance imaging; NLR: Neutrophilto-lymphocyte ratio; OR: Odds ratio ; OS: Overall survival; PE: Pulmonary embolism; PLR: Platelet-to-lymphocyte ratio; PLT: Platelet ; VTE: Venous thromboembolism; WT: Visceral venous thrombosis; WBC: White blood cell

\section{Acknowledgements}

None.

Funding

None.

Availability of data and materials

The datasets used and/or analyzed by the current study are available from the corresponding author on reasonable request.

\section{Authors' contributions}

All authors contributed equally to this work. EJK and JSK designed the concept and methodology of the study. SYL, HJK and DSK collected patient data. JSK and YJC analyzed and interpreted the patient data. EJK, JSK wrote original draft. HYS and JSK reviewed and edited the manuscript. Each author participated sufficiently in the work and received final version of manuscript. All authors approved the final version of manuscript and to be accountable for all aspects of the work.

Ethics approval and consent to participate

This study complies with the ethical standards in Korea. This study was approved by the Institutional Review Board of the Korea University Guro Hospital (KUGH 16320-001). This study was designed as retrospective study using electronic medical records of patients. Because objectives and materials of study did not affect the patient's health and welfare, the institutional review board of our institution permitted to perform this study without patient's consent.

\section{Consent for publication}

Not applicable.

\section{Competing interests}

The authors declare that they have no conflicts of interest relevant to the contents of this manuscript.

\section{Publisher's Note}

Springer Nature remains neutral with regard to jurisdictional claims in published maps and institutional affiliations.

\section{Author details}

${ }^{1}$ Division of Hematology/Oncology, Department of Internal Medicine, Korea University College of Medicine, 148 Gurodong-ro, Guro-gu, Seoul 08308, South Korea. ${ }^{2}$ Division of Hematology/Oncology, Department of Internal Medicine, Korea University College of Medicine, 148 Gurodong-ro, Guro-gu, Seoul 08308, South Korea. ${ }^{3}$ Division of Hematology/Oncology, Department of Internal Medicine, Konkuk University School of Medicine, Chungchungbukdo, Chungju, South Korea.

Received: 11 June 2018 Accepted: 29 November 2018

Published online: 17 December 2018

\section{References}

1. Arshad A, Al-Leswas D, Al-Taan O, Stephenson J, Metcalfe M, Steward WP, Dennison AR. Pooled survival and response data from phase III randomized controlled trials for gemcitabine-based regimes in the treatment of advanced pancreatic cancer. Am J Clin Oncol. 2013;36(4):411-4.

2. Howlader N, Noone A, Krapcho M, Garshell J, Miller D, Altekruse S, Kosary C, Yu M, Ruhl J, Tatalovich Z. SEER Cancer Statistics Review, 1975-2012. Bethesda, MD: National Cancer Institute; 2015.

3. Stein PD, Beemath A, Meyers FA, Skaf E, Sanchez J, Olson RE. Incidence of venous thromboembolism in patients hospitalized with cancer. Am J Med. 2006;119(1):60-8. 
4. Khorana AA, Kuderer NM, Culakova E, Lyman GH, Francis CW. Development and validation of a predictive model for chemotherapy-associated thrombosis. Blood. 2008;111(10):4902-7.

5. Blom JW, Vanderschoot JP, Oostindier MJ, Osanto S, van der Meer FJ, Rosendaal FR. Incidence of venous thrombosis in a large cohort of 66,329 cancer patients: results of a record linkage study. Journal of thrombosis and haemostasis : JTH. 2006;4(3):529-35.

6. Sorensen HT, Mellemkjaer L, Olsen JH, Baron JA. Prognosis of cancers associated with venous thromboembolism. N Engl J Med. 2000;343(25): 1846-50.

7. Di Nisio M, Porreca E, Candeloro M, De Tursi M, Russi I, Rutjes AW. Primary prophylaxis for venous thromboembolism in ambulatory cancer patients receiving chemotherapy. The Cochrane database of systematic reviews. 2016;12:CD008500.

8. Lyman GH, Khorana AA, Kuderer NM, Lee AY, Arcelus Jl, Balaban EP, Clarke $J M$, Flowers CR, Francis CW, Gates LE, et al. Venous thromboembolism prophylaxis and treatment in patients with cancer: American Society of Clinical Oncology clinical practice guideline update. Journal of clinical oncology : official journal of the American Society of Clinical Oncology. 2013;31(17):2189-204.

9. Mandala M, Falanga A, Roila F, Group EGW. Management of venous thromboembolism (VTE) in cancer patients: ESMO clinical practice guidelines. Ann Oncol. 2011;22(Suppl 6):vi85-92.

10. Maraveyas A, Waters J, Roy R, Fyfe D, Propper D, Lofts F, Sgouros J, Gardiner E, Wedgwood K, Ettelaie C, et al. Gemcitabine versus gemcitabine plus dalteparin thromboprophylaxis in pancreatic cancer. Eur J Cancer. 2012; 48(9):1283-92.

11. Munoz Martin AJ, Garcia Alfonso P, Ruperez Blanco AB, Perez Ramirez S, Blanco Codesido M, Martin Jimenez M. Incidence of venous thromboembolism (VTE) in ambulatory pancreatic cancer patients receiving chemotherapy and analysis of Khorana's predictive model. Clinical \& translational oncology : official publication of the Federation of Spanish Oncology Societies and of the National Cancer Institute of Mexico. 2014; 16(10):927-30

12. Lee JC, Ro YS, Cho J, Park Y, Lee JH, Hwang JH, Choi HJ, Lee S. Characteristics of venous thromboembolism in pancreatic adenocarcinoma in east Asian ethnics: a large population-based observational study. Medicine. 2016;95(17):e3472.

13. Shaib W, Deng Y, Zilterman D, Lundberg B, Saif MW. Assessing risk and mortality of venous thromboembolism in pancreatic cancer patients. Anticancer Res. 2010;30(10):4261-4.

14. Mandala M, Reni M, Cascinu S, Barni S, Floriani I, Cereda S, Berardi R, Mosconi S, Torri V, Labianca R. Venous thromboembolism predicts poor prognosis in irresectable pancreatic cancer patients. Ann Oncol. 2007;18(10): 1660-5.

15. Rickles FR, Patierno S, Fernandez PM. Tissue factor, thrombin, and cancer. Chest. 2003;124(3 Suppl):58S-68S.

16. Belting M, Dorrell MI, Sandgren S, Aguilar E, Ahamed J, Dorfleutner A, Carmeliet P, Mueller BM, Friedlander M, Ruf W. Regulation of angiogenesis by tissue factor cytoplasmic domain signaling. Nat Med. 2004;10(5):502-9.

17. Kakkar AK, Chinswangwatanakul V, Lemoine NR, Tebbutt S, Williamson RC. Role of tissue factor expression on tumour cell invasion and growth of experimental pancreatic adenocarcinoma. Br J Surg. 1999;86(7):890-4.

18. Rickles FR, Shoji M, Abe K. The role of the hemostatic system in tumor growth, metastasis, and angiogenesis: tissue factor is a bifunctional molecule capable of inducing both fibrin deposition and angiogenesis in cancer. Int J Hematol. 2001;73(2):145-50.

19. Tomimaru Y, Yano M, Takachi K, Kishi K, Miyashiro I, Ohue M, Ohigashi H, Sasaki Y, Ishikawa O, Imaoka S. Correlation between pretherapeutic d-dimer levels and response to neoadjuvant chemotherapy in patients with advanced esophageal cancer. Diseases of the esophagus : official journal of the International Society for Diseases of the Esophagus. 2008;21(4):281-7.

20. Ho KM, Yip CB, Duff $O$. Reactive thrombocytosis and risk of subsequent venous thromboembolism: a cohort study. Journal of thrombosis and haemostasis : JTH. 2012;10(9):1768-74.

21. Wang Z, Yan HH, Yang JJ, Wang BC, Chen HJ, Zhou Q, Xu CR, Jiang BY, Wu $Y L$. Venous thromboembolism risk factors in Chinese non-small cell lung cancer patients. Supportive care in cancer : official journal of the Multinational Association of Supportive Care in Cancer. 2015;23(3):635-41.

22. Baker D, Sherrod B, McGwin G Jr, Ponce B, Gilbert S. Complications and 30day outcomes associated with venous thromboembolism in the pediatric
Orthopaedic surgical population. The Journal of the American Academy of Orthopaedic Surgeons. 2016;24(3):196-206.

23. Verso M, Agnelli G, Barni S, Gasparini G, LaBianca R. A modified Khorana risk assessment score for venous thromboembolism in cancer patients receiving chemotherapy: the Protecht score. Intern Emerg Med. 2012;7(3):291-2.

24. Ay C, Dunkler D, Marosi C, Chiriac AL, Vormittag R, Simanek R, Quehenberger P, Zielinski C, Pabinger I. Prediction of venous thromboembolism in cancer patients. Blood. 2010;116(24):5377-82.

25. van Es N, Franke VF, Middeldorp S, Wilmink JW, Buller HR. The Khorana score for the prediction of venous thromboembolism in patients with pancreatic cancer. Thromb Res. 2017;150:30-2.

26. Park K, Ryoo BY, Ryu MH, Park SR, Kang MJ, Kim JH, Han S, Kang YK. Incidence of venous thromboembolism and the role of D-dimer as predictive marker in patients with advanced gastric cancer receiving chemotherapy: a prospective study. World journal of gastrointestinal oncology. 2017;9(4):176-83.

\section{Ready to submit your research? Choose BMC and benefit from:}

- fast, convenient online submission

- thorough peer review by experienced researchers in your field

- rapid publication on acceptance

- support for research data, including large and complex data types

- gold Open Access which fosters wider collaboration and increased citations

- maximum visibility for your research: over $100 \mathrm{M}$ website views per year

At $\mathrm{BMC}$, research is always in progress.

Learn more biomedcentral.com/submissions 